RESEARCH REPORT

\title{
Regional variation and time trends in mortality from ischaemic heart disease: East and West Germany 10 years after reunification
}

\author{
J Müller-Nordhorn, K Rossnagel, W Mey, S N Willich
}

J Epidemiol Community Health 2004;58:481-485. doi: 10.1136/jech.2003.013367

\begin{abstract}
See end of article for authors' affiliations

Correspondence to: Dr J Müller-Nordhorn, Institute of Social Medicine, Epidemiology and Health Economics, Luisenstraße 57, D-10117 Berlin, Germany; jacqueline.muellernordhorn@charite.de
\end{abstract}

Accepted for publication 25 August 2003

\begin{abstract}
Study objective: Within Europe, a pronounced geographical gradient of mortality from ischaemic heart disease has been observed with the highest burden in the north east and the lowest in the south west. The study objective was to compare mortality from ischaemic heart disease between former East and West Germany since reunification.

Design: Analyses of age standardised mortality rates from ischaemic heart disease (ICD-9 410-414, ICD10 I20-125) between 1990-1991 and 2000.

Setting: Former East and West Germany.

Main results: After a peak in the early 1990s, mortality from ischaemic heart disease has substantially declined in both parts of Germany (from 222 to 169 per 100000 in the East and from 150 to 116 per 100000 in the West). The regional difference, however, remained rather constant: the rate ratio between the pooled mortality in the East compared with the West was $1.51(95 \% \mathrm{Cl} 1.46$ to 1.56$)$ in 1991 and $1.45(95 \% \mathrm{Cl} 1.39$ to 1.50$)$ in 2000 . These rate ratios were higher in women (1.63 in 1991 and 1.52 in 2000 ) compared with men (1.45 and 1.44, respectively).

Conclusions: Within Germany, there has been a pronounced east-west gradient of mortality from ischaemic heart disease since reunification. Further insight into possible underlying reasons may lead to improved preventive strategies.
\end{abstract}

$\mathrm{T}$ he fall of the Berlin wall in 1989 and the subsequent reunification of East (former German Democratic Republic) and West (former Federal Republic of Germany) Germany in 1990 led to major socioeconomic and political changes for the people living in the country. The population in the East experienced a rapid transition from a socialist to a capitalist government with effects on all aspects of life including employment, income, housing, nutrition, and medical care. The reunification offers the unique historical situation to investigate trends in life expectancy and mortality in people with similar cultural background and genetic origin who were divided for decades and then reunified.

Life expectancy between East and West Germany had started to diverge in the mid-1970s largely attributable to an improving life expectancy in the former West Germany, whereas life expectancy almost stagnated in the East. ${ }^{1}$ Furthermore, East German life expectancy took an intermediate position between the life expectancy in West European countries and the life expectancy in other East and Central European countries such as Poland or Hungary. ${ }^{2}$ Cardiovascular diseases and particularly ischaemic heart disease accounted for about half of the east-west difference in life expectancy. ${ }^{2-4}$ Overall, mortality from ischaemic heart disease within Europe exhibits a pronounced gradient with the highest burden in the north east and the lowest in the south west. ${ }^{3-5}$ Previous studies reported a variety of potential explanations such as regional differences in blood pressure, smoking, diet and alcohol consumption, socioeconomic factors, medical care, and air pollution..$^{25-9}$ Regional variation even exists within countries such as a north-south gradient in mortality from ischaemic heart disease in both Britain and France. ${ }^{1011}$ Morris et al quantified the contribution of individual risk factors to the regional variation in Britain and concluded that up to three quarters of the regional variance could be attributed to the combined effects of smoking (the single most important factor), physical activity, systolic blood pressure, occupational social class, and height. However, factors for regional variation may be different in other areas. In a study by Bobak et al comparing risk factors in Czech, Bavarian, and Israeli men, smoking was not significantly different between the three countries, whereas blood pressure appeared to be a major factor for explaining regional variation. ${ }^{6}$

The aim of this study was to determine regional variation and time trends in mortality from ischaemic heart disease in Germany since reunification, with particular focus on differences between East and West Germany.

\section{METHODS}

For the time period from 1990 to 2000, the Federal Statistical Office of Germany, Wiesbaden, provided mortality rates from ischaemic heart disease per 100000 based on the primary death certificate diagnosis. For the years 1990-1997, the coding for ischaemic heart disease of the ninth revision of the International Classification of Diseases (ICD-9 410-414), and for the years 1998-2000, of the tenth revision (ICD-10 I20I25) was applied.

For age standardisation, the European standard population (1976) was taken. The weights used for standardisation by five year age groups (19 age groups) were $1.6(<1$ year), 6.4 ( $1-4$ years), 7 ( $5-54$ years), 6 (55-59 years), 5 (60-64 years), 4 (65-69 years), 3 (70-74 years), 2 (75-79 years), 1 (80-84 years), 0.8 (85-90 years), and 0.2 (90+ years). ${ }^{12}$ The same weights were used for males, females and all persons.

Mortality rates were analysed according to state of residence, time period, and subcategories of ischaemic heart disease. Rate ratios and 95\% confidence intervals (CI) were calculated for the respective comparisons. For the analysis according to state of residence, we divided age standardised 
mortality rates (2000) into quintiles. Additionally, we compared the state with the highest to the state with the lowest mortality rate.

For the comparison over time (1990-2000), we analysed age standardised mortality rates for the aggregated East and West German states. Before reunification, the City State of Berlin had been divided into an eastern and western part. However, we excluded Berlin from the analysis of time trends as administrative units started to change in the late 1990s making a differentiation into East and West Berlin impossible. Time trends in age standardised mortality rates are shown separately for the age groups $25-64$ years and $\geqslant 65$ years. In addition, the two main diagnoses of ischaemic heart disease, acute myocardial infarction (I21-22) and chronic ischaemic heart disease (I25), were analysed separately.

\section{RESULTS}

\section{Mortality rates according to state of residence}

Mortality from ischaemic heart disease varied largely according to state of residence. Analysing the age standardised mortality rates from ischaemic heart disease in 2000 , there was a pronounced gradient with the highest burden in the north east and the lowest in the south west (fig l). The states with the highest mortality rates were Brandenburg, Mecklenburg-Western Pomerania, and Saxony-Anhalt in the north east whereas the lowest mortality rates were reported for Baden-Wuerttemberg in the south west and the two City States of Berlin and Hamburg. The state of Saarland although situated in the south west had a comparatively high mortality rate in the second highest quintile. In men, the rate ratio between the state Saxony-Anhalt with the highest mortality rate from ischaemic heart disease (246 per 100000$)$ and the state Baden-Wuerttemberg with the lowest mortality rate ( 139 per 100000 ) was 1.78 (95\% CI 1.72 to 1.84 ). In women, the rate ratio between the state Saxony-Anhalt with the

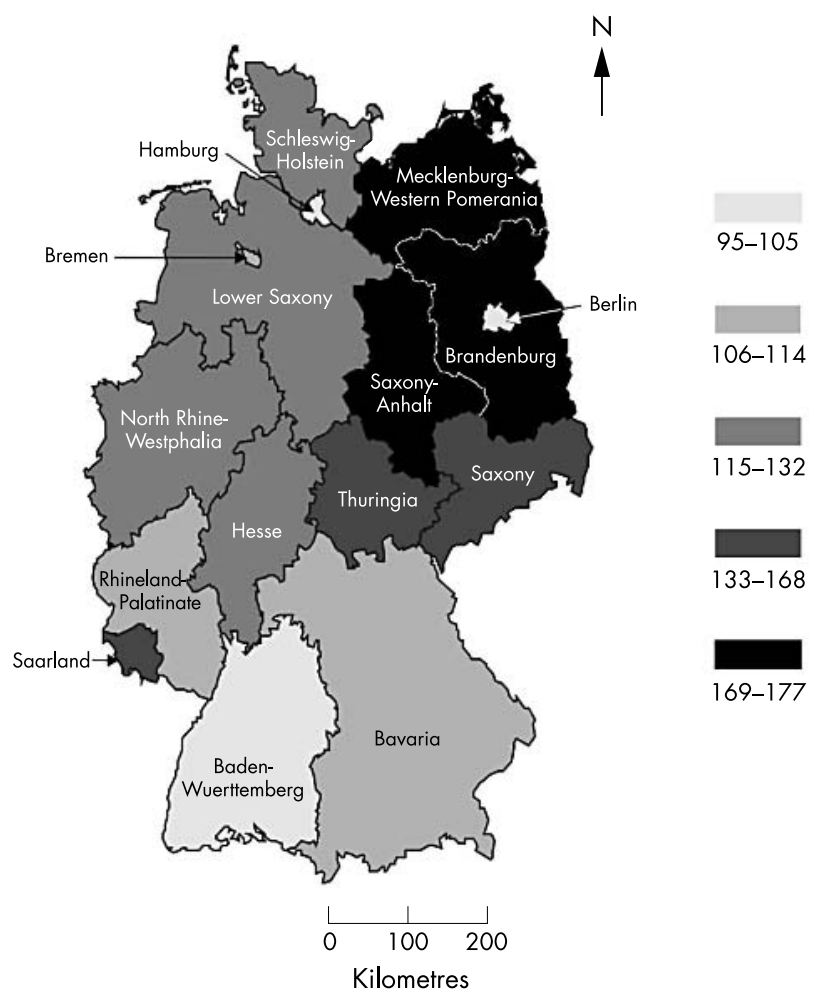

Figure 1 Age standardised mortality rates (all ages) from ischaemic heart disease per 100000 (2000) according to state; the European standard population (1976) was used for standardisation. highest mortality rate ( 133 per 100000 ) and the state BadenWuerttemberg with the lowest mortality rate (65 per 100000 ) was 2.03 (95\% CI 1.95 to 2.12 ).

\section{Time trends}

Time trends (1990-2000) in age standardised mortality rates from ischaemic heart disease showed some differences between East and West Germany. In West Germany, mortality from ischaemic heart disease decreased continuously between 1990 and 2000 (table 1). In East Germany, on the other hand, a sharp increase in mortality from ischaemic heart disease was observed between 1990 and 1991 followed by a peak in 1993. The rate ratio between the pooled mortality in the East versus the West, however, remained rather constant: 1.51 (95\% CI 1.46 to 1.56 ) in 1991 and 1.45 (95\% CI 1.39 to 1.50 ) in 2000. Rate ratios were higher for women compared with men (table 1). Time trends showed a similar pattern in sex specific age groups (fig $2 \mathrm{~A}$ and $\mathrm{B}$ ). In the age group 25-64 years, the rate ratio between East and West Germany was 1.34 (95\% CI 1.16 to 1.54 ) in 2000 and the rate difference 13 per 100000 . In the age group $\geqslant 65$ years, the respective rate ratio was 1.47 (95\% CI 1.42 to 1.52 ) and the rate difference 410 per 100000 .

\section{Mortality rates according to diagnosis}

Mortality from ischaemic heart disease was mainly attributable to the diagnoses acute myocardial infarction (I21-22) and chronic ischaemic heart disease (I25). Mortality from the other diagnoses of ischaemic heart disease (I20, I23, I24) was very low. Rate ratios between East and West Germany were higher for chronic ischaemic heart disease compared with acute myocardial infarction, particularly in women (table 2).

\section{DISCUSSION}

Ten years after reunification, mortality from ischaemic heart disease is still about $50 \%$ higher in East compared with West Germany. In the West, mortality from ischaemic heart disease has continuously decreased throughout the 1990s whereas in the East, mortality peaked during the early 1990s, and is now gradually declining.

The observed difference in mortality from ischaemic heart disease seems unlikely to be caused to a large extent by migration or differences in coding procedures after 1990/91. Migration might have resulted in healthy people leaving the East to live in the West. Overall, about one million East Germans migrated to the West during and after reunification. ${ }^{13}$ However, the vast majority of the migrants were young, with less than $10 \%$ being older than 50 years. Therefore, provided that the demographic denominator was estimated correctly, migration does not seem to contribute largely to the observed difference in mortality. With regards to coding, the regulations of the WHO manual were often disregarded in the former German Democratic Republic. ${ }^{14}$ Diagnoses such as hypertension and atherosclerosis were coded as causes of death despite the presence of an underlying ischaemic heart disease resulting in an underestimation of ischaemic heart disease. To quantify the magnitude of miscoding, Heinemann et al recoded 4154 death certificates (1986) in the East German state of Saxony..$^{14}$ They found that ischaemic heart disease was coded correctly in only $71 \%$ in men and $59 \%$ of women and calculated a correction factor for official mortality rates of 1.5 in men and 1.6 in women. Since October 1990, statistical offices uniformly classify the causes of death in Germany according to the WHO manual. The sharp increase in mortality in East Germany between 1990 and 1991 is likely to be partly caused by this change in coding procedures. However, mortality rates from ischaemic heart disease still 
Table 1 Time trends in age standardised mortality rates from ischaemic heart disease (I20-125) per 100000 (all ages); the European standard population (1976) was used for standardisation

\begin{tabular}{|c|c|c|c|c|c|c|c|c|c|c|c|c|}
\hline \multirow[b]{2}{*}{ Year } & \multicolumn{4}{|l|}{ Total } & \multicolumn{4}{|l|}{ Men } & \multicolumn{4}{|c|}{ Women } \\
\hline & West & East & Rate ratio & $95 \% \mathrm{Cl}^{*}$ & West & East & Rate ratio & $95 \% \mathrm{Cl}$ & West & East & Rate ratio & $95 \% \mathrm{Cl}$ \\
\hline 1990 & 150 & 167 & 1.11 & 1.07 to 1.16 & 221 & 247 & 1.12 & 1.09 to 1.16 & 104 & 118 & 1.14 & 1.09 to 1.18 \\
\hline 1991 & 145 & 218 & 1.51 & 1.46 to 1.56 & 214 & 311 & 1.45 & 1.41 to 1.50 & 99 & 162 & 1.63 & 1.57 to 1.69 \\
\hline 1992 & 142 & 215 & 1.51 & 1.46 to 1.57 & 209 & 305 & 1.45 & 1.41 to 1.50 & 98 & 160 & 1.63 & 1.57 to 1.69 \\
\hline 1993 & 143 & 222 & 1.55 & 1.50 to 1.61 & 210 & 321 & 1.53 & 1.49 to 1.58 & 99 & 162 & 1.64 & 1.58 to 1.70 \\
\hline 1994 & 136 & 221 & 1.62 & 1.57 to 1.68 & 199 & 317 & 1.59 & 1.55 to 1.64 & 95 & 163 & 1.72 & 1.66 to 1.78 \\
\hline 1995 & 135 & 221 & 1.64 & 1.58 to 1.70 & 196 & 314 & 1.60 & 1.55 to 1.65 & 94 & 164 & 1.75 & 1.69 to 1.81 \\
\hline 1996 & 131 & 210 & 1.60 & 1.54 to 1.66 & 190 & 298 & 1.57 & 1.52 to 1.62 & 92 & 157 & 1.70 & 1.64 to 1.77 \\
\hline 1997 & 130 & 196 & 1.51 & 1.46 to 1.56 & 186 & 276 & 1.48 & 1.44 to 1.53 & 92 & 147 & 1.60 & 1.54 to 1.66 \\
\hline 1998 & 129 & 190 & 1.47 & 1.42 to 1.53 & 184 & 266 & 1.45 & 1.40 to 1.49 & 91 & 144 & 1.57 & 1.52 to 1.63 \\
\hline 1999 & 124 & 180 & 1.45 & 1.39 to 1.50 & 176 & 250 & 1.42 & 1.37 to 1.46 & 88 & 136 & 1.54 & 1.48 to 1.60 \\
\hline 2000 & 116 & 169 & 1.45 & 1.39 to 1.50 & 165 & 238 & 1.44 & 1.40 to 1.49 & 83 & 126 & 1.52 & 1.47 to 1.58 \\
\hline
\end{tabular}

increased after 1991 suggesting that a "real" peak occurred and not only an artefact.

Diagnostic uncertainty may be reflected by the use of the ICD category ill defined causes (R00-99) with ischaemic heart disease being the most probable underlying cause of death. ${ }^{15}$ Age standardised mortality rates from ill defined causes of death have been higher in West compared with East Germany (22 versus 9 per 100000 in 2000). ${ }^{16}$ On the other hand, the rate ratio between East and West Germany has been greater for "chronic ischaemic heart disease", as an entity of higher diagnostic uncertainty, than for "acute myocardial infarction". If mortality rates from ill defined causes were added to the diagnosis "chronic ischaemic heart disease", the respective rate ratio between the East and the West would decrease from 1.52 to 1.22. East and West

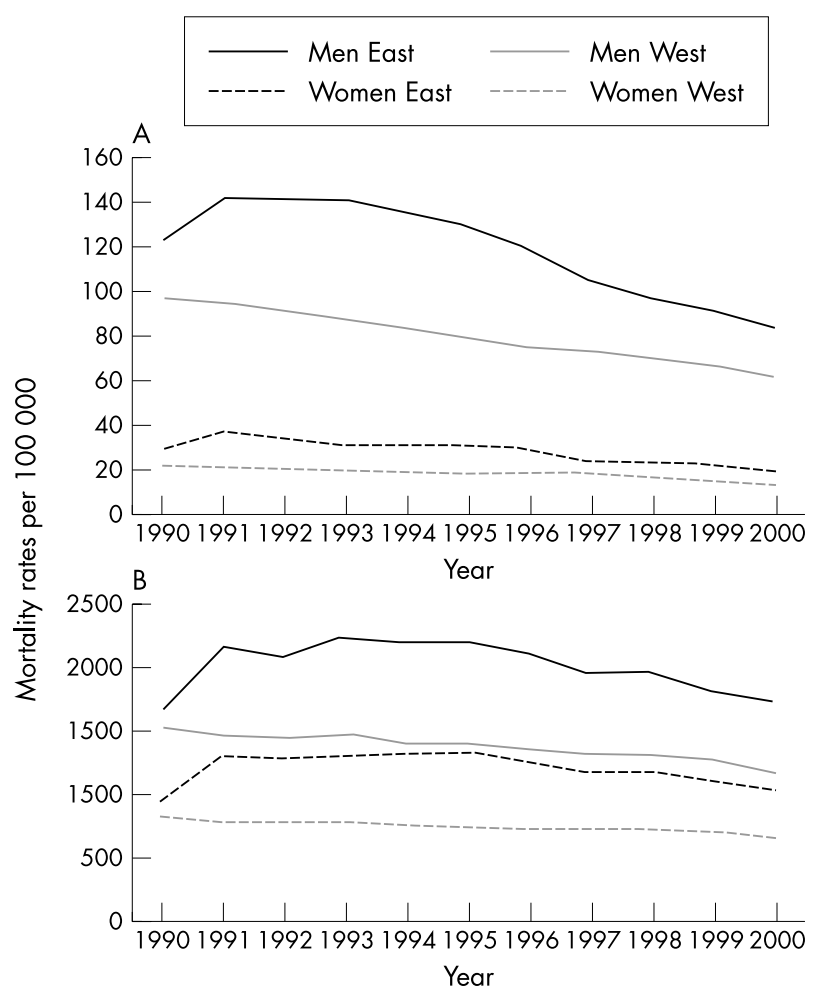

Figure 2 Age standardised mortality rates from ischaemic heart disease in the age groups 25 to $64(A)$ and $\geqslant 65$ years (B); the European standard population (1976) was used for standardisation. Note that the $y$ axes of $A$ and $B$ have different dimensions.
German physicians seem to use different approaches to diagnostic uncertainty.

\section{Possible explanations}

Possible underlying reasons for regional variation in mortality from ischaemic heart disease include differences in classic coronary risk factors, lifestyle, psychosocial factors, environment, and medical care. ${ }^{10}{ }^{17-20}$ The existence of a time lag of several years between the change in a risk factor and the incidence of ischaemic heart disease has to be taken into account. ${ }^{1821}$ In patients with an already existing ischaemic heart disease, the change in a risk factor or major external events can precipitate acute coronary syndromes or even serve as a trigger. ${ }^{22}$ This may have led to the observed peak in mortality from ischemic heart disease in the East after the reunification. We will, therefore, discuss risk factors in East and West Germany both before and after the reunification. The comparison of risk factors for the time period before and during the reunification is limited because of the sparsity of uniformly acquired data. There are, however, some studies such as the international WHO MONICA (monitoring trends and determinants in cardiovascular disease) Project in both East and West Germany and the National Health Surveys providing valuable insight into the distribution of cardiovascular risk factors. ${ }^{18}{ }^{23-27}$

Some differences in pathophysiological coronary risk factors such as hypercholesterolaemia, hypertension, diabetes, and obesity were observed between the East and the West. Higher cholesterol concentrations were observed in the East compared with the West for both men and women before the reunification, however, the difference seems to have largely disappeared in the mid-1990s. ${ }^{18} 232628$ Blood pressure, on the other hand, has continuously been higher in the East compared with the West both before and after the reunification. ${ }^{1} 823252930$ In the 1990s, diabetes was far more prevalent in the East compared with the West. ${ }^{30-32}$ Preunification data on the prevalence of diabetes were rarely published. Obesity has been reported for a higher percentage of East compared with West Germans during the 1980s and 1990s. ${ }^{23} 2533$

Lifestyle factors such as smoking, physical activity, and diet also differed between the East and the West. During the 1980s and early 1990s, smoking was the one cardiovascular risk factor with a more favourable profile in the East, mainly in women. ${ }^{18} 23252834$ However, the prevalence of smoking is now similar in the East and the West. ${ }^{34}$ In the 1998 National Health Survey, physical activity during leisure time was slightly more common in West compared with East German participants. ${ }^{35}$ As to diet, the availability of certain foods on the market had been limited in East Germany before the reunification as well as in other East European countries such 
Table 2 Age standardised mortality rates per 100000 of acute myocardial infarction and chronic ischemic heart disease (2000); the European standard population (1976) was used for standardisation

\begin{tabular}{lllll}
\hline Ischaemic heart disease & West & East & Rate ratio & $\mathbf{9 5} \% \mathbf{C l}^{*}$ \\
\hline Total & & & & \\
Acute myocardial infarction (I21-122) & 57 & 76 & 1.32 & 1.24 to 1.40 \\
Chronic ischaemic heart disease (I25) & 59 & 90 & 1.52 & 1.46 to 1.59 \\
Men & 85 & 118 & 1.38 & 1.31 to 1.45 \\
$\begin{array}{l}\text { Acute myocardial infarction (I21-I22) } \\
\text { Chronic ischaemic heart disease (I25) }\end{array}$ & 79 & 115 & 1.46 & 1.40 to 1.53 \\
Women & 37 & 47 & 1.29 & 1.21 to 1.39 \\
Acute myocardial infarction (I21-122) & 46 & 76 & 1.67 & 1.60 to 1.75 \\
Chronic ischaemic heart disease (I25) & & & & \\
\hline *Confidence intervals & & &
\end{tabular}

as Poland. ${ }^{9}$ The consumption of vegetable oil and margarine, fresh vegetables, and tropical fruits was lower in the East than in the West, whereas the intake of sausages and fat, in particular butter, was much higher. ${ }^{36}{ }^{37}$ Alcohol consumption also varied with a higher intake of beer and wine in the West and spirits in the East. ${ }^{36}$ After reunification, a western dietary pattern was adopted in the East although some residual differences seem to persist. ${ }^{38} 39$

Differences between the East and the West could also be observed for psychosocial factors such as stressful life events, socioeconomic status, and social support. ${ }^{40-43}$ Stressful life events such as feelings of insecurity at work or serious financial trouble were reported more frequently by East compared with West Germans. ${ }^{40-42}$ As to socioeconomic status, per capita income, gross domestic product (GDP), and unemployment have consistently been less favourable in the East compared with the West. ${ }^{43}{ }^{44}$ The GDP per state follows a clear north east to south west gradient with a higher GDP in the south western states with the exception of the state of Saarland. ${ }^{44}$ This may partially explain the higher mortality rates from ischaemic heart disease in the state of Saarland. Furthermore, the prevalence of unemployment in Saarland is among the highest in the western states, although still considerably lower than in the eastern states. Social support by a partner and/or friends and a more fulfilling family life, on the other hand, were reported more frequently by East than West German residents. ${ }^{40}{ }^{42}$

Associations between air pollution and long term increases in cardiovascular mortality rates have been reported..$^{19}$ Before the reunification, East Germany had considerably higher levels of inhalable particulates and sulphur dioxides (especially in Saxony, Saxony-Anhalt, Thuringia) compared with West Germany. ${ }^{45}$ The famous "Black Triangle" in southern Saxony (East Germany), northern Bohemia and Moravia (Czech Republic), and part of lower Silesia (Poland) was one of the most polluted areas in central Europe. ${ }^{46}$ Boback et al

\section{Key points}

- There is a pronounced north east and south west gradient of mortality from ischaemic heart disease within Germany.

- Even a decade after reunification, mortality rates are still about $50 \%$ higher in the East compared with the West.

- It seems that the population in the East has had decades of higher exposure to most known cardiovascular risk factors. However, further research into the underlying reasons is needed. estimated that $9 \%$ of the all cause mortality gap between the Czech Republic and Western Europe could be attributed to air pollution. ${ }^{47}$ During the 1990s, particulates and sulphur dioxides have been successfully reduced in East Germany, for example, by replacing brown coal and other solid fossil fuels with central heating.

Between the mid-1980s and the mid-1990s, major developments occurred in coronary care in both primary and secondary prevention. In the WHO MONICA Project, eight of these treatments were combined in a treatment score. ${ }^{17}$ In the mid-1980s, treatment scores were similar between East and West German MONICA centres. In the mid-1990s, however, treatment scores in the West German centres were considerably higher compared with the scores in the East German centre. Other western countries also showed higher treatment scores compared with eastern countries. Overall, improvements in treatment score and mortality from ischaemic heart disease showed a strong inverse correlation. However, a quantification of the attribution of medical care to the observed trends in mortality from ischaemic heart disease was not possible in this ecological analysis. In Germany, some differences in medical care seem to persist despite a general healthcare system, for example, a lower number of coronary angiographies per million population in the East. ${ }^{48}$

\section{Strengths and limitations}

For this study, we used routinely obtained mortality rates. There are some inherent problems with the use of secondary data as they are not primarily assessed for the study purpose and often have lower data quality. However, the WHO MONICA Project confirmed the validity of official mortality rates from ischaemic heart disease. ${ }^{49}$ An advantage of using mortality rates, on the other hand, is that they are available not only for selected study populations but for the whole German population and are updated on a yearly basis. Because of the lack of uniformly acquired data, the variety of risk factors associated with ischaemic heart disease, and the ecological nature of most comparisons, any attempt to explain the observed differences in mortality can only be done with caution. It seems, however, that the population in

\section{Policy implications}

- The identification of those factors responsible for most of the variation in mortality might help to target public health measures.

- Regional variation in mortality should be taken into account when developing national guidelines for the prevention of ischaemic heart disease. 
the East has had decades of higher exposure to most known cardiovascular risk factors. A quantification of the contribution of individual risk factors might help to reduce the prominent East-West gap in the long term. ${ }^{7}$

\section{Conclusion}

Further research is needed to identify those factors responsible for most of the variation in mortality and to quantify their attributable risk. The results might help to target public health measures as well as to allocate healthcare resources more effectively.

\section{ACKNOWLEDGEMENTS}

We thank the Federal Statistical Office of Germany, Wiesbaden, for providing standardised mortality rates from ischaemic heart disease.

\section{Authors' affiliations}

J Müller-Nordhorn, K Rossnagel, S N Willich, Institute of Social Medicine, Epidemiology and Health Economics, Charité University Medical Centre, Berlin, Germany

W Mey, Gesellschaft für sozialmedizinische Forschung, Suhl, Germany Conflicts of interest: none declared.

\section{REFERENCES}

1 Nolte E, Shkolnikov V, McKee M. Changing mortality patterns in East and West Germany and Poland. I: long term trends (1960-1997). J Epidemiol Community Health 2000;54:890-8.

2 Bobak M, Marmot M. East-West mortality divide and its potential explanations: proposed research agenda. BMJ 1996;312:421-5.

3 Uemura K, Pisa Z. Trends in cardiovascular disease mortality in industrialized countries since 1950. World Health Stat Q 1998;41:155-78.

4 Sans $\mathrm{S}$, Kesteloot $\mathrm{H}$, Kromhout $\mathrm{H}$. The burden of cardiovascular diseases mortality in Europe. Eur Heart J 1997; 18:1231-48.

5 Kesteloot H, Sasaki S, Zhang X, et al. Mortality trends: a comparison between Denmark, Hungary and Japan. Acta Cardiol 1995;50:343-67.

6 Bobak M, Hense HW, Kark J, et al. An ecological study of determinants of coronary heart disease rates: a comparison of Czech, Bavarian and Israeli men. Int J Epidemiol 1999;28:437-44.

7 Kesteloot H. Changes in all-cause and cardiovascular mortality rates in Eastern Europe: a missed opportunity. Acta Cardiol 2001;56:273-5.

8 Kroumhout D. Epidemiology of cardiovascular diseases in Europe. Public Health Nutr 2001:4:441-57.

9 Zatonski WA, McMichael AJ, Powles JW. Ecological study of reasons for sharp decline in mortality from ischemic heart disease in Poland since 1991 BMJ 1998;316:1047-51

10 Morris RW, Whincup PH, Lampe FC, et al. Geographic variation in incidence of coronary heart disease in Britain: the contribution of established risk factors. Heart 2001;86:277-83.

11 Lang T, Ducimetière $P$, Arveiler D, et al. Trends and geographical disparities in coronary heart disease in France: are results concordant when different definitions of events are used? Int J Epidemiol 1999;28:1050-8.

12 Waterhouse J, Correa P, Muir C, et al. Cancer incidence in five continents. Vol 3. Lyon: International Agency for Research on Cancer, 1976;6:456.

13 Federal Statistical Office. Population and employment. Fachserie 1 Reihe 1. Wiesbaden: Federal Statistical Office, 1999.

14 Heinemann L, Barth W, Löwel H. On the validity of the cardiovascular mortality statistics of the former GDR. Z Gesundheitswissenschaften 1998;2:108-19.

15 Armstrong DL, Wing SB, Tyroler HA. United States mortality from ill-defined causes, 1968-1988: potential effects on heart diseases mortality trends. Int J Epidemiol 1995;24:522-7

16 Federal Statistical Office. Federal health monitoring system. Wiesbaden: 2003. http://www.gbe-bund.de.

17 Tunstall-Pedoe $H$, Vanuzzo $D$, Hobbs $M$, et al. Estimation of contribution of changes in coronary care to improving survival, event rates, and coronary heart disease mortality across the WHO MONICA Project populations. Lancet 2000;355:688-700

18 Kuulasmaa K, Tunstall-Pedoe H, Dobson A, et al. Estimation of contribution of changes in classic risk factors to trends in coronary-event rates across the WHO MONICA Project populations. Lancet 2000;355:675-87.
19 Dockery DW, Pope CA 3rd, Xu X, et al. An association with air pollution and mortality in six U.S. cities. N Engl J Med 1993;329:1753-9.

20 Willich SN, Löwel H, Mey W, et al. Regional variations in mortality from cardiovascular diseases in Germany. Dtsch Ärzteb/ 1999;96:A483-8.

21 Rose G. Incubation period of coronary heart disease. BMJ 1982;284:1600-1.

22 Willich SN, Klatt S, Arntz HR. Circadian variation and triggers of acute coronary syndromes. Eur Heart J 1998; 19(suppl): 12-23.

23 Marti B, Rickenbach $M$, Keil U, et al. Variation in coronary risk factor levels of men and women between the German-speaking MONICA centres. Rev Epidemiol Sante Publique 1990;38:479-86.

24 Heinemann LA, Garbe E, Classen E, et al. Trends in cardiovascular risk factors in East Germany: three independent population studies as part of the project MONICA East Germany. Dtsch Med Wochenschr 1998;123:889-95.

25 Heinemann LA, Greiser EM. Blood pressure, hypertension, and other risk factors in East and West Germany. Ann Epidemiol 1993;3(suppl):90-5.

26 Hoffmeister H, Bellach BM. Die Gesundheit der Deutschen. RKI-Heft 7/1995. Berlin: Robert-Koch Institut, 1995

27 Thefeld W, Stolzenberg H, Bellach BM. German National Health Interview and Examination Survey: Response, composition of participants, and analysis of non-respondents. Gesundheitswesen 1999;61(suppl):57-61.

28 Jaross W, Assmann G, Bergmann S, et al. Comparison of risk factors for coronary heart disease in Dresden and Münster. Eur J Epidemiol 1994; 10:307-15.

29 Thamm M. Blood pressure in Germany-update review of state and trends. Gesundheitswesen 1999;61(suppl):90-3.

30 Fischer F, Schiele R, Zahn R, et al. Myocardial infarction in 1996-1998: a comparison between the "old" and "new" Lands of Germany. Disch Med Wochenschr 2000;125:1181-5.

31 Thefeld W. Prevalence of diabetes mellitus in adults in Germany. Gesundheitswesen 1999;61(suppl):85-9.

32 Zentralinstitut für die kassenärztliche Vereinigung in der Bundesrepublik Deutschland. Gesundheitszustand und ambulante medizinische Versorgung der Bevölkerung im Ost-West-Vergleich. Publikationsreihe "Wissenschaftliche Reihe" Band 56. Köln: Deutscher Ärzte-Verlag, 2000.

33 Bergmann KE, Mensink GB. Anthropometric data and obesity. Gesundheitswesen 1999;61(suppl):115-20.

34 Junge B, Nagel M. Das Rauchverhalten in Deutschland. Gesundheitswesen 1999;61(suppl):121-5.

35 Mensink GBM. Physical activity. Gesundheitswesen 1999;61(suppl):126-31.

36 Thiel C, Heinemann L. Nutritional behaviour differences in Germany. Rev Environ Health 1996;11:35-40.

37 Winkler G, Holtz H, Döring A. Comparison of food intakes of selected populations in former East and West Germany: results from the MONICA Projects Erfurt and Augsburg. Ann Nutr Metab 1992;36:219-34.

38 Winkler G, Brasche S, Döring A, et al. Dietary intake of middle-aged men from an East and a West German city after the German reunification: do differences still exist? Eur J Clin Nutrition 1998;52:98-103.

39 Hellenbrand W, Baver $\mathrm{G}$, Boeing $\mathrm{H}$, et al. Diet in residents of East and West Germany in 1991-1992 as ascertained by a retrospective food frequency questionnaire. Soz Präventivmed 2000:45:13-24.

40 Hillen T, Schaub R, Hiestermann A, et al. Self rating in health is associated with stressful life events, social support and residency in East and West Berlin shortly after the fall of the wall. $J$ Epidemiol Community Health 2000;54:575-80.

41 Lüschen G, Geling O, Janssen C, et al. After unification: gender and subjective health status in East and West Germany. Soc Sci Med 1997;44:1313-23

42 Ellert U, Knopf H. Satisfaction with living conditions and health. Gesundheitswesen 1999:61(suppl):145-50.

43 Statistische Ämter der Länder. Volkswirtschaffliche Gesamtrechnungen der Länder. Entstehung, Verteilung und Verwendung des Bruttoinlandsprodukts in den Ländern und Ost-West-Großraumregionen Deutschlands 1991-2001. Stuttgart: Statistisches Landesamt Baden-Wuerttemberg, 2002

44 Federal Statistical Office. Statistical yearbook 2001 for the Federal Republic of Germany. Stuttgart: Metzler-Poeschel, 2001

45 Umweltbundesamt. Umweltdaten Deutschland 2002. Berlin: Umweltbundesamt, 2002.

46 Renner E. The Black Triangle area-fit for Europe? Numerical air quality studies for the Black Triangle area. Ambio 2002;31:231-5

47 Bobak M, Feachem RGA. Air pollution and mortality in Central and Eastern Europe. Eur J Public Health 1995;5:82-6.

48 Perleth M, Mannebach H, Busse R, et al. Cardiac catheterization in Germany Diffusion and utilization from 1984 to 1996. Int J Technol Assess Health Care 1999; 15:756-66.

49 Tunstall-Pedoe H, Kuulasmaa K, Mähönen M, et al. Contribution of trends in survival and coronary event rates to changes in coronary heart disease mortality: 10-year results from $37 \mathrm{WHO}$ MONICA Project populations. Lancet 1999;353:1547-57. 